\title{
Experimental Investigation on Sensitivity of Smart Aggregate Embedded in Reinforced Concrete Beam
}

\author{
Shruti R. Gedam, Suraj N. Khante* \\ Applied Mechanics Department, Government College of Engineering Amravati, Maharashtra, India \\ Email: shruti.gedam27@gmail.com, *snkhante@yahoo.com
}

How to cite this paper: Gedam, S.R. and Khante, S.N. (2016) Experimental Investigation on Sensitivity of Smart Aggregate Embedded in Reinforced Concrete Beam. Open Journal of Civil Engineering, 6, 653-669. http://dx.doi.org/10.4236/ojce.2016.64053

Received: June 13, 2016

Accepted: September 26, 2016

Published: September 29, 2016

Copyright $\odot 2016$ by authors and Scientific Research Publishing Inc. This work is licensed under the Creative Commons Attribution International License (CC BY 4.0).

http://creativecommons.org/licenses/by/4.0/

\section{(c) (i) Open Access}

\begin{abstract}
Electromechanical impedance (EMI) based lead zirconate titanate (PZT) is an effective sensor to ensure the safety of structure. In civil engineering community, Reinforced Concrete (RC) structure is one of the most familiar engineering structures. Hence, it is very important to monitor the health of structure. In this paper, a new approach of structural health monitoring using embedded PZT in host structure is proposed. There are several issues while embedding PZT inside RC structure which are examined during study. This paper presents two experimental studies on lab sized concrete beams. First implementation was carried out with different methods of embedment of PZT and its sensitivity study when the host structure was subjected to damage. The second implementation was verified in terms of conductance sensitivity of embedded Smart Aggregate (SMAG) in varying orientation i.e. horizontal $\left(0^{\circ}\right)$ and vertical $\left(90^{\circ}\right)$ after embedding in RC beam. The electrical conductance and susceptance signatures of different embedded PZT transducers were measured and damage index was calculated by using Root Mean Square Deviation Method.
\end{abstract}

\section{Keywords}

Concrete, Impedance, Piezoelectric Materials, Sensors, Smart Aggregates

\section{Introduction}

Around the world, health monitoring of concrete structure has been playing an important role in the development of civil engineering. Structural Health Monitoring (SHM) is a process of monitoring the present condition of engineering structures. Many techniques for SHM have been reported in recent years. Moreover, there are several conflicts while monitoring health of concrete structure. This paper presents a new ap- 
proach of health monitoring of structure based on electromechanical impedance (EMI) technique using embedded PZT sensors.

Earlier several authors have also proposed the SHM by using PZT smart sensors. Shanker [1] proposed the experimental study on embedded PZT as a sensor by using EMI technique. A simple low cost experimental technique was developed to extract the experimental strain mode shapes of the structure directly by using a surface bonded and embedded PZT sensor. It was found that damage ranging from incipient to near failure (severe) can be located and quantified by using the EMI technique and the experimental mode shapes with desired accuracy. Annamdas et al. [2] proposed a method of embedding PZT sensor in concrete for monitoring concrete. The implementation was verified on various lab sized concrete cubes and the observations were examined by statistical analysis. Wang et al. [3] proposed a health monitoring method based on EMI measurements, which used the electromechanical coupling property of embedded PZT transducers. Khante and Gedam [4] experimentally monitored the health of RC structure by embedding indigenously prepared PZT based smart aggregate in two phases i.e. for healthy and damaged state of RC specimen. Dumoulin et al. [5] studied crack propagation in a reinforced concrete beam by using PZT sensor. Two different types of excitation signals were used (pulse and chirp) and the resulting waves were recorded on the receivers. Based on these signals, different damage indicators were investigated and compared. Kaur et al. [6] investigated the integrity of the low-cost EMI technique and the global vibration technique for health assessment. Fourteen CVS were embedded inside a RC beam, while casting, to obtain the first curvature mode shape of the RC beam. A mode shape curvature based algorithm was adopted for damage detection and severity assessment. Song et al. [7] proposed the smart aggregates as a multifunctional tool for health monitoring. A damage index based on the wavelet packet analysis was used to determine the structural health status. Negi et al. [8] oriented PZT patches in different configuration in host structure. Visalakshi and Bhalla [9] proposed a comparison between the sensing capabilities of surface bonded and embedded piezoceramic (PZT) patches in corrosion assessment for RC structures. Accelerated corrosion tests were performed on RC specimens, and the statistical index and the equivalent parameters were compared for the two types of sensor configurations. B. Xu et al. [10] proposed a PZT based active interface debonding defect detection approach for multi-chamber Steel Reinforced Concrete (SRC) columns and validated experimentally with an irregular multi-chamber SRC specimen. A number of embedded piezo-based functional elements (EPFEs) installed close to the steel plates and piezoelectric ceramic (PZT) patches bonded on the surface of the steel plates were used as actuators and sensors respectively. Based on the amplitude of the measurement of the PZT patches under sinusoidal excitations and the wavelet packet energy under sweep sinusoidal signals, the interface debonding defects was detected successfully. Zhu et al. [11] presented the design and fabrication processes of EMI sensors embedded into concrete structures. Based on the electrical admittance and strain measurements, the health statuses of the continuous rigid frame bridge was monitored and evaluated successfully in the construction 
and operation stages by using a root-Mean-Square Deviation (RMSD) index. Gupta et al. [12] discussed a newly developed approach for detecting and quantifying corrosion of steel bars utilizing a piezoelectric ceramic (PZT) patch surface bonded on the rebar employing equivalent structural parameters using the Electro-Mechanical Impedance (EMI) technique.

By using conventional and EMI techniques, a lot of experimental and analytical work has been done by many researchers for health monitoring of structures. Electro-mechanical impedance technique is considered more reliable and convenient for structural health monitoring. In previous studies, a limited experimental work using embedded PZT was carried out on the structures. Hence, in this paper, an attempt is made to study preparation of indigenous embedded SMAG and the feasibility of EMI technique for in situ SHM. This research article presents EMI approach using a new variant of the embedded SMAG for non-destructive monitoring of concrete structures. The conductance and susceptance signatures acquired over input frequency range are the basis for assessing the health of real-life RC structures.

\section{Health Monitoring Based on Electro-Mechanical Impedance (EMI) Technique}

The piezoelectric patch has a unique property to act as both sensor and actuator and can be easily surface bonded or embedded inside host structure. When mechanical stress is applied on PZT patch it produces an electrical charge, which is called as direct piezoelectric effect of PZT. The governing principle of EMI based health monitoring method is to monitor the changes in structure by measuring admittance signature of EMI active sensor bonded onto or embedded into the structure as shown in Figure 1.

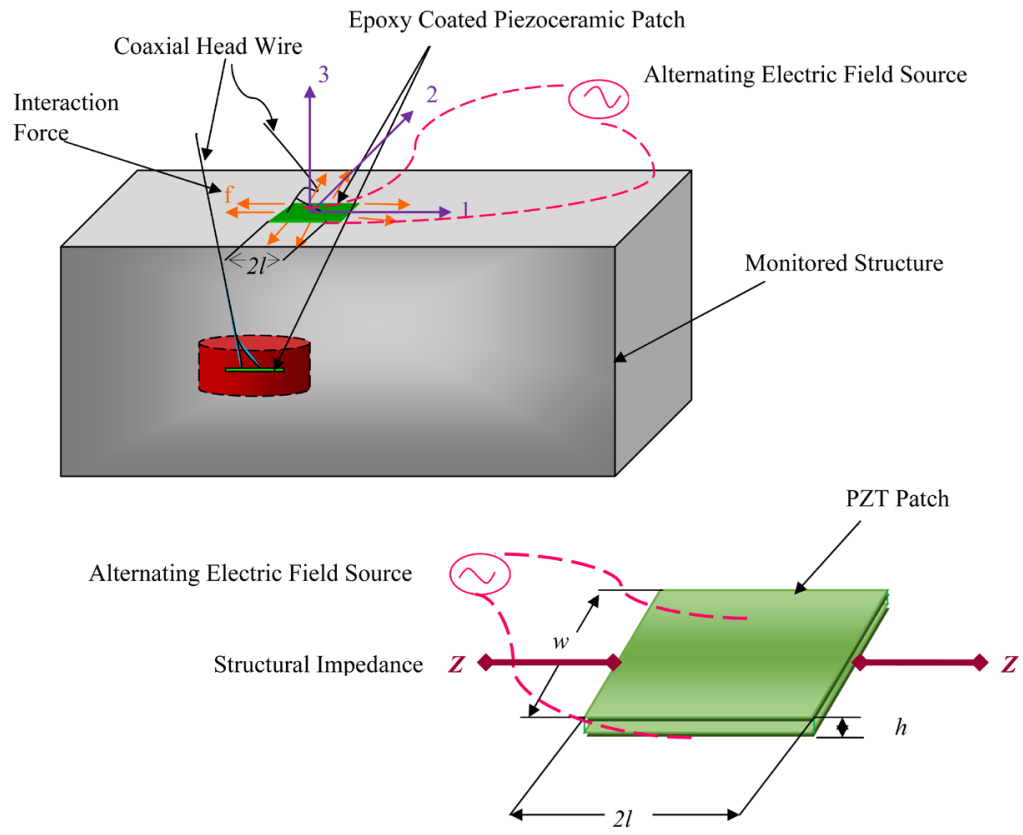

Figure 1. PZT structure interaction [12]. 
Equation (1) below represents the complex electro-mechanical admittance $\bar{Y}$ of the system.

$$
\bar{Y}=2 \omega j \frac{w l}{h}\left[\left(\varepsilon_{33}\right)^{T}+\left(\frac{Z a}{Z+Z a}\right)\left(d_{31}\right)^{2} \bar{Y}^{E}\left(\frac{\tan k l}{k l}\right)-\left(d_{31}\right)^{2} \bar{Y}^{E}\right]
$$

where, $l, w$ and $h$ are the length, width and thickness of the PZT patch respectively, $j$ being imaginary number equal to $(\sqrt{-1}), \omega$ is angular frequency and $k l$ is the wave number, $\left(\varepsilon_{33}\right)^{T}$ is the complex electric permittivity at constant stress, $Z_{a}$ is mechanical impedance of the PZT patch, $d_{31}$ is the piezoelectric strain coefficient of the PZT material, $\bar{Y}^{E}$ is the complex Young's modulus under constant electric field, $Z$ is the mechanical impedance of the host structure.

In EMI based method, high frequencies in the order of few $\mathrm{kHz}$ to hundred $\mathrm{kHz}$ are used. Mechanical impedance of the host structure is the function of its mass, stiffness, and damping properties. Any changes in admittance signature indicate the presence of structural damage and simultaneously structural properties also changes. The electroechanical admittance $Y$ consists of the real and the imaginary component called conductance and susceptance respectively. Hence, the magnitude of complex admittance can be calculated as given in Equation (2):

$$
Y=\sqrt{G^{2}+B^{2}}
$$

where, $G=$ Conductance; real part of admittance,

$B=$ Susceptance; imaginary part of admittance.

Damage characterization is accomplished by using root mean square deviation method (RMSD). Electrical impedance signatures are compared with each other in which one of the signature known as baseline signature is acquired when the structure is considered to be healthy. The RMSD index compares baseline signature and signature obtained in damaged condition of structure measured over preset frequency range respectively. RMSD of the signature is given by Equation (3),

$$
M=\sqrt{\frac{\sum\left(G_{2}-G_{1}\right)^{2}}{\sum G_{1}^{2}}} \times 100(\%)
$$

where, $M=$ Damage metric (Root Mean Square Deviation),

$G_{1}=$ Conductance before damage,

$G_{2}=$ Conductance after damage.

\section{Fabrication of Embedded Smart Aggregate (SMAG)}

Smart Aggregates (SMAGs) are thin PZT transducers casted in small mortar pieces. The PZT transducer is very fragile and can be easily damaged by the vibrator during the casting of concrete structures. The robust PZT patch should be protected in the form of smart aggregate and embedded at the desired position in the concrete structure before casting, eliminating the risk of damaging the transducer during the vibrating process. The method of fabrication was carried out as explained below.

Step 1: A typical PZT patch of size $10 \times 10 \times 0.2 \mathrm{~mm}$ and $5 \mathrm{H}$ grade manufactured by Central Electronics Limited, Sahibabad, Delhi was selected to embed into structure. 
One of the ends of coaxial head wire was soldered to the electrodes of PZT patch. The soldered wires were then connected to impedance analyzer via connecting fixture for recording admittance signature over the user specified frequency range. Admittance signature of free PZT patches was recorded to ensure proper working.

Step 2: Encapsulation of waterproofed PZTs i.e. SMAG were formed in two ways as follows:

SMAG Brick: A hollow rectangular shaped card board mould of $50 \times 25 \times 25 \mathrm{~mm}$ size was prepared and a five sided rich mortar rectangular box with $5 \mathrm{~mm}$ side thickness maintaining its top portion open was casted as shown in Figure 2 and allowed to cure for 3 days. The free PZT was then positioned inside one of the side of box using epoxy adhesive to make it waterproof and surface from outside was marked for identification and allowed to (air) cure for 24 hours. Finally, the top layer of box was closed, still maintaining inner portion as hollow. After 24 hours of casting the mould was then allowed to (water) cure for 23 days.

Metal Wire SMAG Cylinder: Firstly two perpendicular galvanised steel wires of length $100 \mathrm{~mm}$ and diameter $1 \mathrm{~mm}$ were fixed on top of PZT patch using epoxy adhesive and also remaining portion of PZT patch was coated with epoxy adhesive to make it waterproof and allowed to (air) cure for 24 hours as shown in Figure 3(a). After curing its admittance signatures were obtained. A card board mould of $20 \mathrm{~mm}$ diameter was prepared and filled to its half depth with mortar and the waterproofed PZT patch with galvanised steel wire was then placed over it. Then the second half layer over PZT was filled with mortar and mould was allowed to (water) cure for 28 days as shown in Figure 3(b).

The admittance signatures were again recorded to check any damage incurred during this fabrication process. The robust encapsulated PZT was referred as Smart Aggregate (SMAG) to embed into host structure. If there was any abnormality other than appearances of new modes in signature occurs it would be regarded as failed SMAG. Again the same procedure needs to be performing to fabricate a new SMAG. After completion of these steps the SMAG was ready to embed inside concrete specimen. A typical concrete vibration sensor (CVS) made by Central Electronics Limited, Sahibabad, Delhi shown in Figure 4 was also used to embed in host structure with the fabricated SMAG.

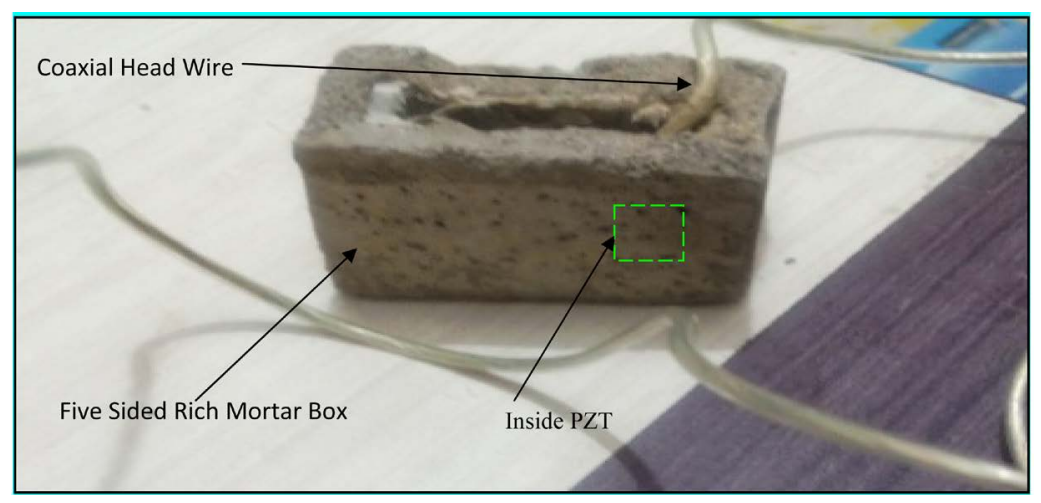

Figure 2. Smart Aggregate transducers; details of different layers. 


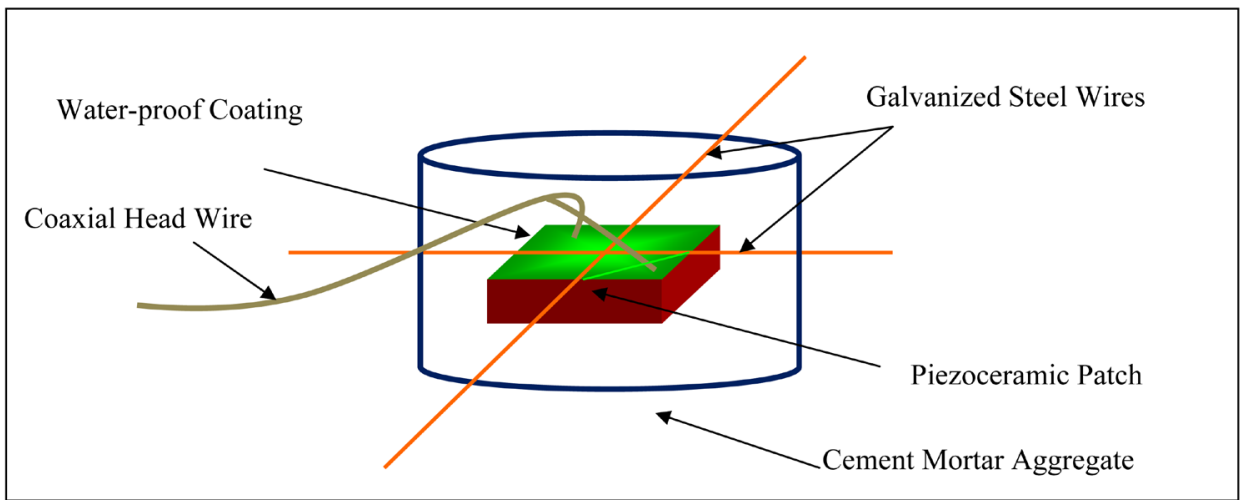

(a)

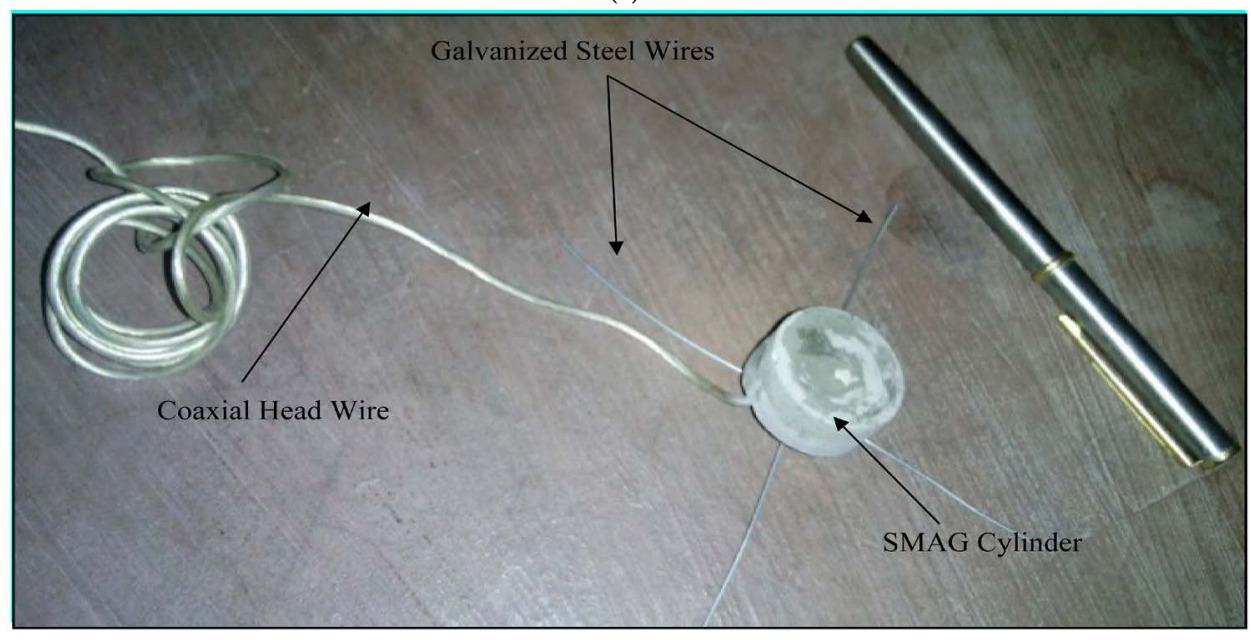

(b)

Figure 3. (a) Metal wire SMAG cylinder; details of different layers. (b) Metal wire SMAG cylinder Transducer.

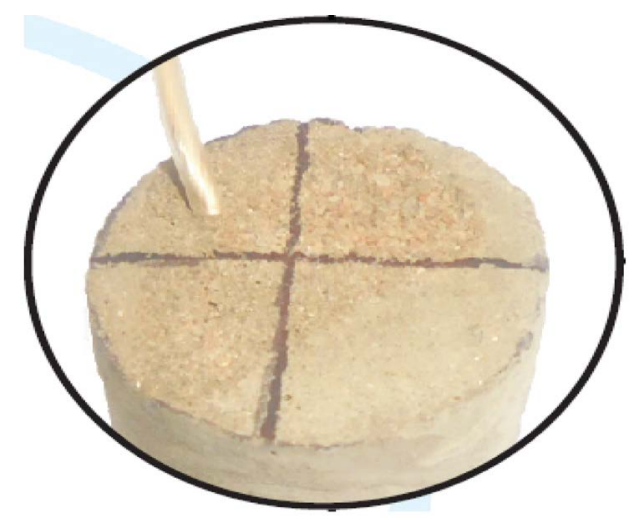

Figure 4. Concrete Vibration Sensor (CVS).

\section{Experimental Setup for Embedded SMAG Based SHM Investigation}

To perform SHM using EMI technique, the instrument used was digital Impedance Analyzer (LCR meter E4980A) having frequency range of $20 \mathrm{~Hz}$ to $2 \mathrm{MHz}$ and its con- 
necting fixture, along with a USB cable and VEE Pro 9.32 for data acquisition system as shown in Figure 5. The tests were performed for the healthy state of host structure and then for damaged state of structure. $100 \mathrm{~mm} \times 100 \mathrm{~mm} \times 410 \mathrm{~mm}$ reinforced concrete beams with M20 grade concrete and Fe 415 steel were monitored. The reinforcement provided was $2 \times 8 \mathrm{~mm} \phi \mathrm{Fe} 415$ steel bars at top and at bottom along with stirrups of Fe 250, $6 \mathrm{~mm} \phi @ 80 \mathrm{~mm}$ c/c. The Maximum Size of Aggregate (MSA) was limited to $20 \mathrm{~mm}$. Test specimen was cured for 7 days. Two different experimental studies were performed on two RC beams in which first study was the comparative study of RC beam with CVS and indigenously prepared SMAG brick and metal wire SMAG cylinder and the second study was conductance sensitivity investigations on SMAG embedded in varying orientation and surface bonded PZT.

\subsection{Comparative Study of RC Beam with CVS and Indigenously Prepared SMAG Brick and Metal Wire SMAG Cylinder}

A simply supported RC beam was casted with embedded metal wire SMAG cylinder and CVS located at $100 \mathrm{~mm}$ distance from left end of beam and $30 \mathrm{~mm}$ distance from top of beam. SMAG brick was embedded at $100 \mathrm{~mm}$ distance from right end of beam and $30 \mathrm{~mm}$ distance from the top of beam. The locations of SMAGs are as shown in Figure 6.

The conductance (G) and susceptance (B) of SMAG and CVS were directly measured through impedance analyzer for the frequency range of $100 \mathrm{kHz}$ to $400 \mathrm{kHz}$. From the obtained data, the graph of conductance versus frequency and susceptance versus frequency were plotted. These graphs were said to be the conductance signature and susceptance signature or just a signature shown by particular sensor for specimen. This data was saved in excel format and can be available as and when required. The damage was introduced by loading the specimen under Universal Testing Machine (UTM) in the form of significant visible crack as shown in Figure 7 and the conductance and susceptance signatures were obtained for damaged specimen. The conductance and susceptance for healthy state and damaged state were compared.

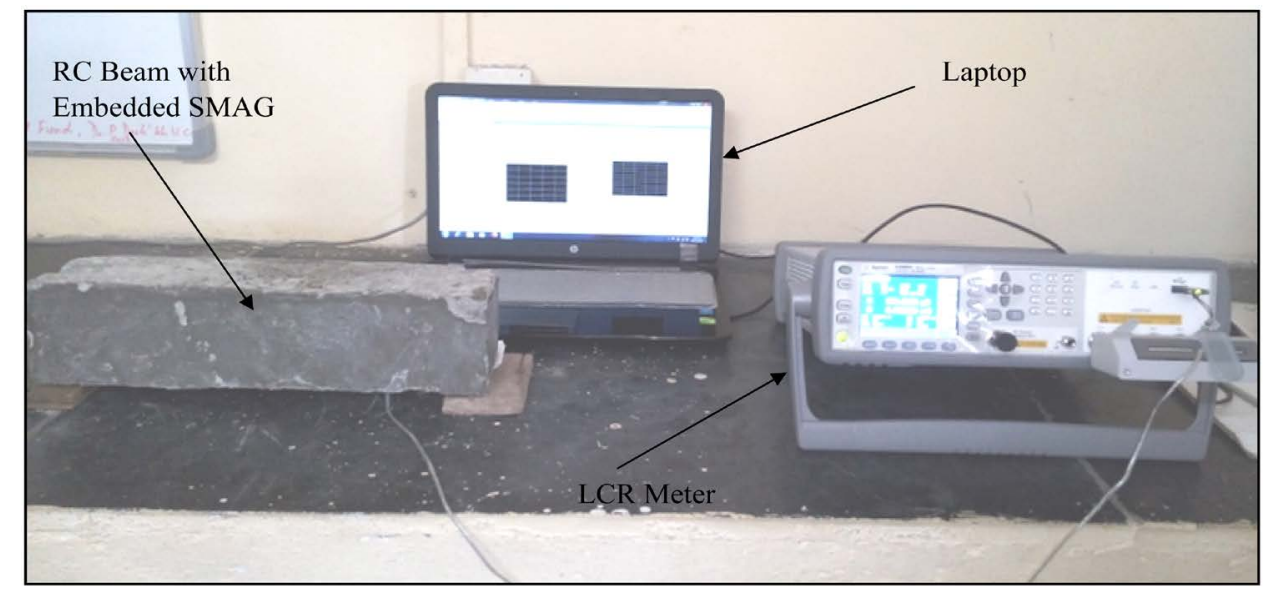

Figure 5. Experimental setup of EMI technique. 


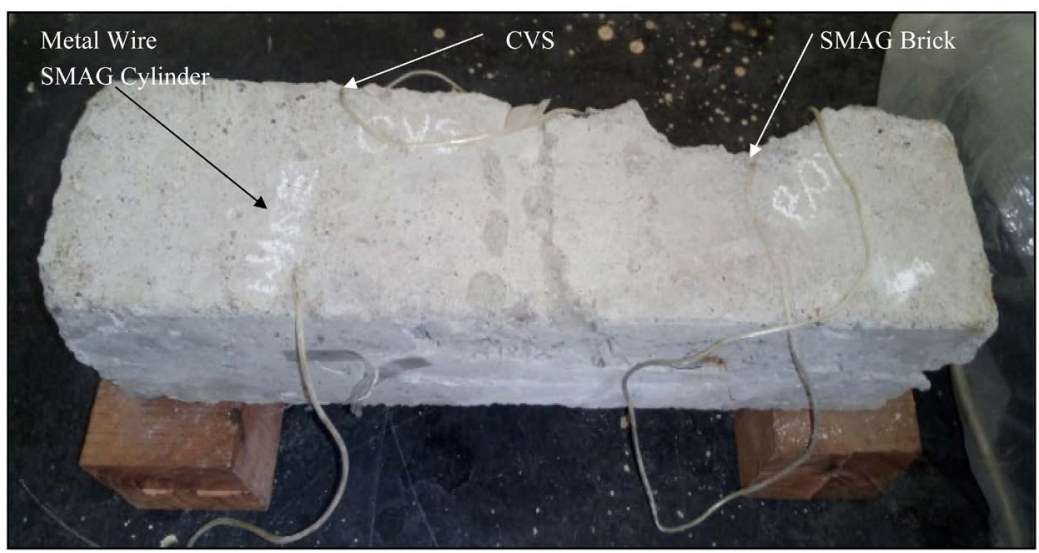

Figure 6. RC beam with embedded SMAG brick, metal wire SMAG cylinder and CVS.

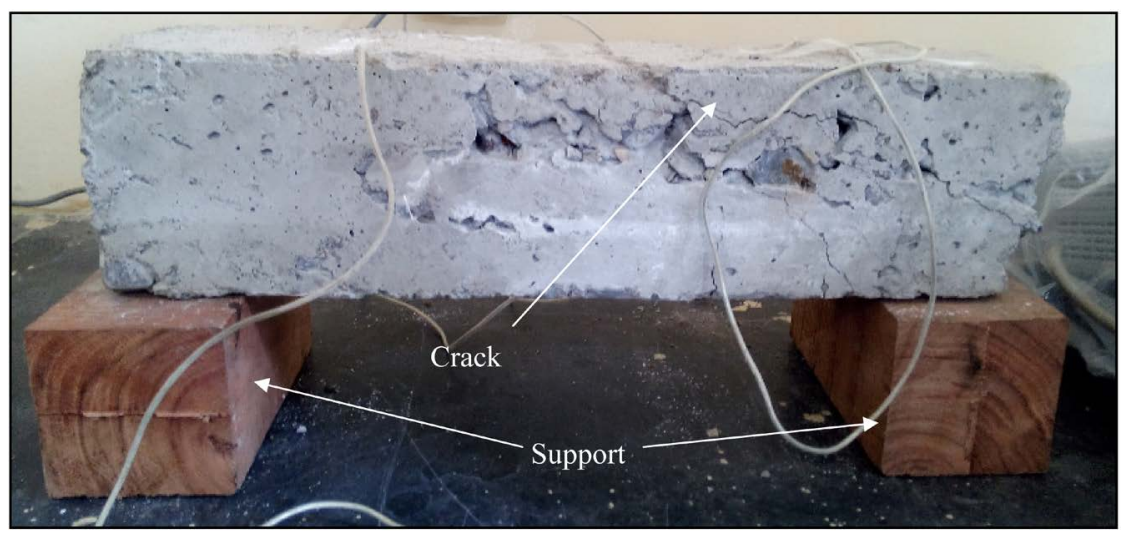

Figure 7. Damaged RC beam.

\subsection{Conductance Sensitivity Investigations on SMAG Embedded in Varying Orientation and Surface Bonded PZT Headings}

For this beam, embedded SMAG brick was used same as shown in Figure 2. Two SMAG bricks were embedded in RC beam below $30 \mathrm{~mm}$ from top of beam, first was at $160 \mathrm{~mm}$ from right end of beam and positioned at $0^{\circ}$ with horizontal i.e. d31 mode. In $\mathrm{d} 31$ mode, response is measured across the poling direction (dir-3) and strain is applied along longitudinal direction (dir-1). Second SMAG was embedded at $170 \mathrm{~mm}$ from right end of beam and positioned at $90^{\circ}$ with horizontal i.e. $\mathrm{d} 33$ mode. In $\mathrm{d} 33$ mode, both response and application of strain are measured across the poling direction. Figure 8 shows plan of SMAG Brick and Figure 9 shows elevation of SMAG Brick. The typical block diagram of RC beam with embedded $0^{\circ}$ SMAG brick and $90^{\circ}$ SMAG brick is shown in Figure 10. Also PZT patch was surface bonded at $160 \mathrm{~mm}$ from right end of beam as shown in Figure 11. Damage in RC beam was introduced by using UTM as shown in Figure 12.

The data for healthy state and different damaged states were compared for all the specimens in the frequency range of $100 \mathrm{kHz}$ to $400 \mathrm{kHz}$. The program of VEE PRO 9.32 directly gives the plot of Conductance versus Frequency and Susceptance versus Frequency. 


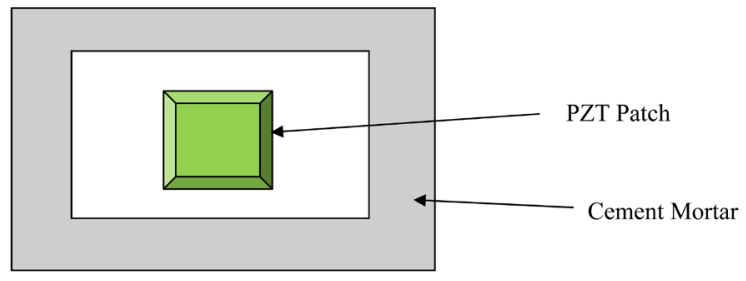

Figure 8. Plan of SMAG brick

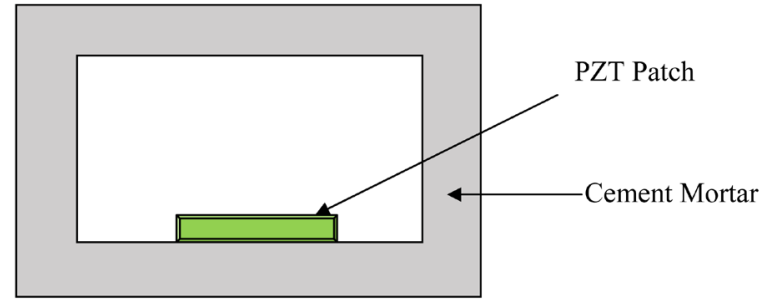

Figure 9. Elevation of SMAG brick.

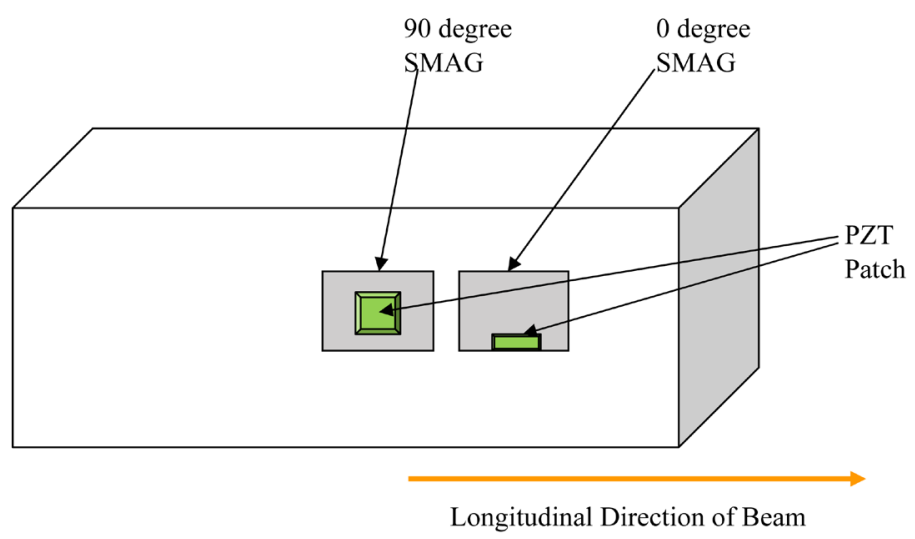

Figure 10. Typical block diagram of RC beam with embedded $0^{\circ}$ SMAG brick and $90^{\circ}$ SMAG brick.

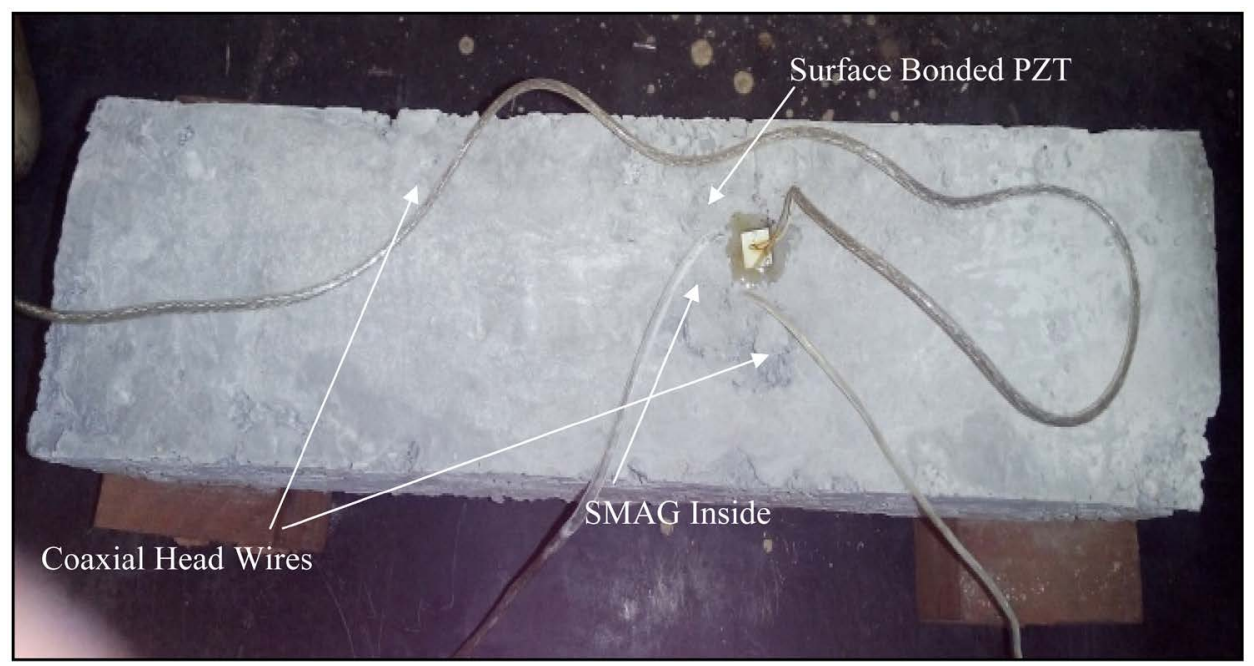

Figure 11. RC beam with embedded SMAG in $\mathrm{d}_{31}$ and $\mathrm{d}_{33}$ mode and surface bonded PZT. 


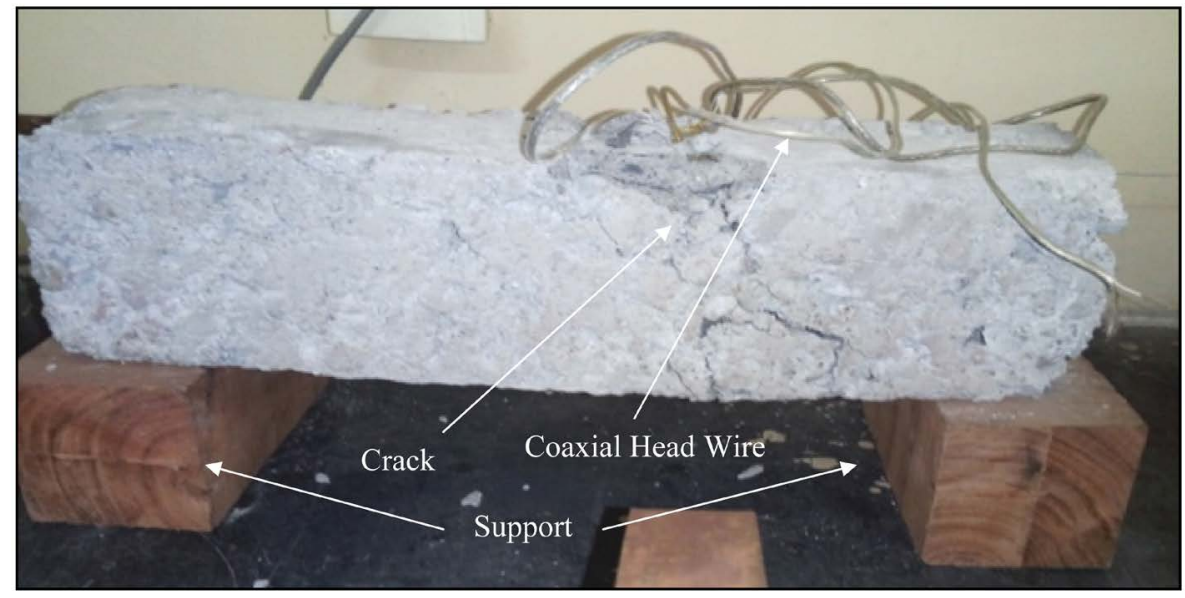

Figure 12. Damaged RC beam with embedded SMAG in $d_{31}$ and $d_{33}$ mode and surface bonded PZT.

\section{Results and Discussion}

The Conductance, susceptance and RMSD index were plotted for all the embedded SMAG, for healthy and damaged condition. VEE Pro 9.32 software was used for data acquisition and data processing.

\subsection{Healthy and Damaged Condition Response of RC Beam with CVS and Indigenously Prepared SMAG Brick and Metal Wire SMAG Cylinder}

\subsubsection{Response for Healthy and Damaged Condition of Embedded SMAG and CVS}

The healthy and damaged response of structure was obtained, with the SMAG brick, metal wire SMAG cylinder and CVS embedded in simply supported RC beam. In the frequency range of 100 to $400 \mathrm{kHz}$, corresponding conductance and susceptance values were recorded by impedance analyzer. Figure 13 and Figure 14 show conductance and susceptance signature for healthy and damaged beam by embedded SMAG brick. Figure 15 and Figure 16 show conductance and susceptance signature for healthy and damaged beam by embedded metal wire SMAG cylinder. Figure 17 and Figure 18 show conductance and susceptance signature for healthy and damaged beam by embedded CVS.

It was found that SMAG brick gives precise results than metal wire SMAG cylinder, may be due to presence of SMAG brick near to damage than metal wire SMAG cylinder and CVS. In this case, SMAG brick was $80 \mathrm{~mm}$ away from the crack while metal wire SMAG cylinder and CVS being $120 \mathrm{~mm}$ away from the crack.

It was observed from the conductance and susceptance signatures that the embedded SMAG shows damage sensitivity with the lateral and vertical shifting of the peaks in damaged and healthy signatures. It was also found from conductance signatures as shown in Figure 13, Figure 15 and Figure 17 that, first peak occurs in frequency range of $100-200 \mathrm{kHz}$ for SMAG brick and metal wire SMAG cylinder whereas; CVS gives first peak in between $200-300 \mathrm{kHz}$ frequency. 


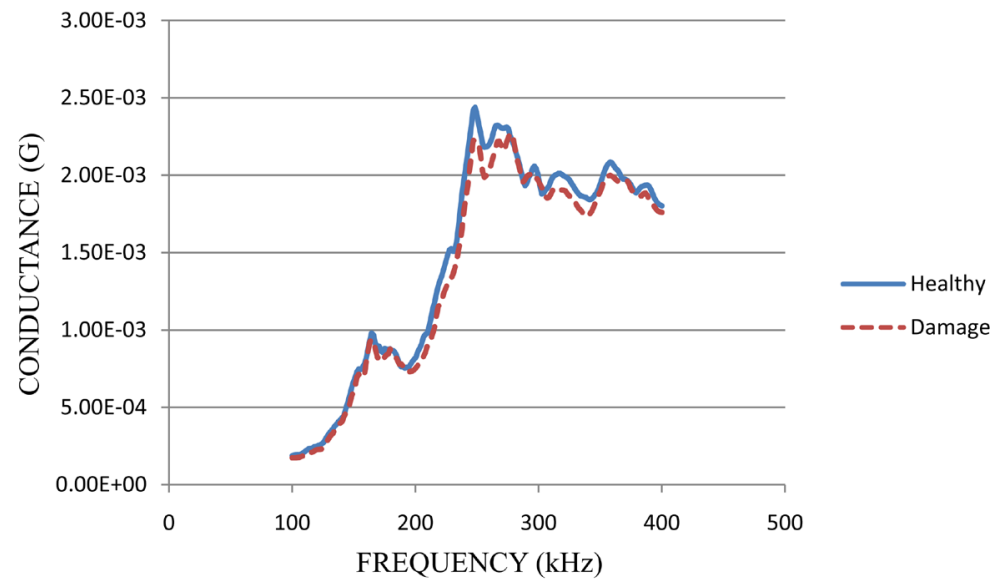

Figure 13. Conductance signature for healthy and damaged beam by embedded SMAG brick.

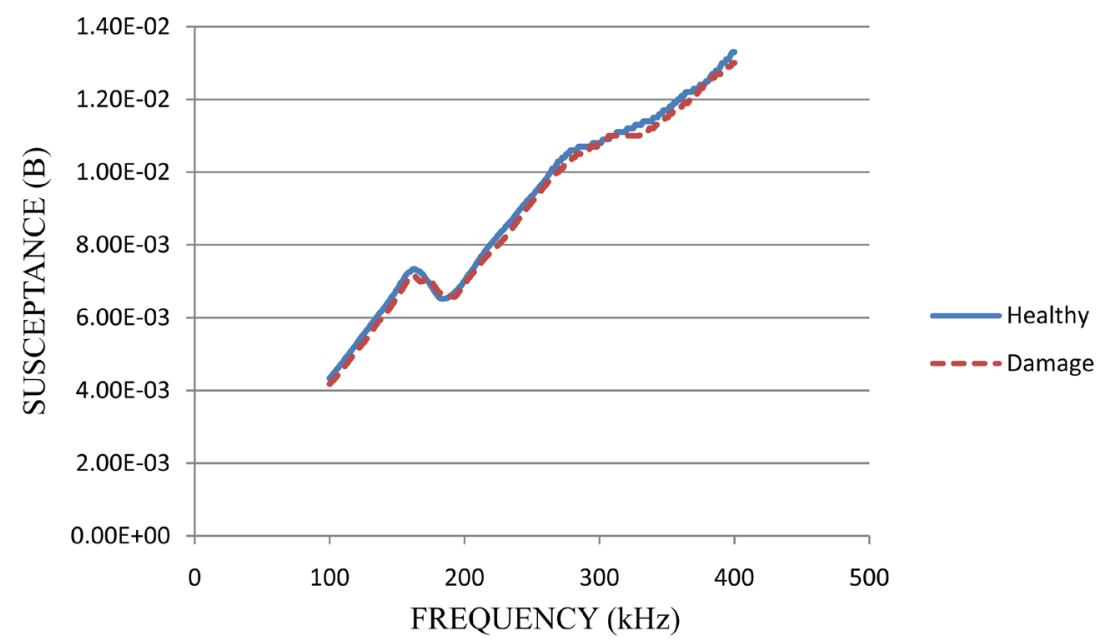

Figure 14. Susceptance signature for healthy and damaged beam by embedded SMAG brick.

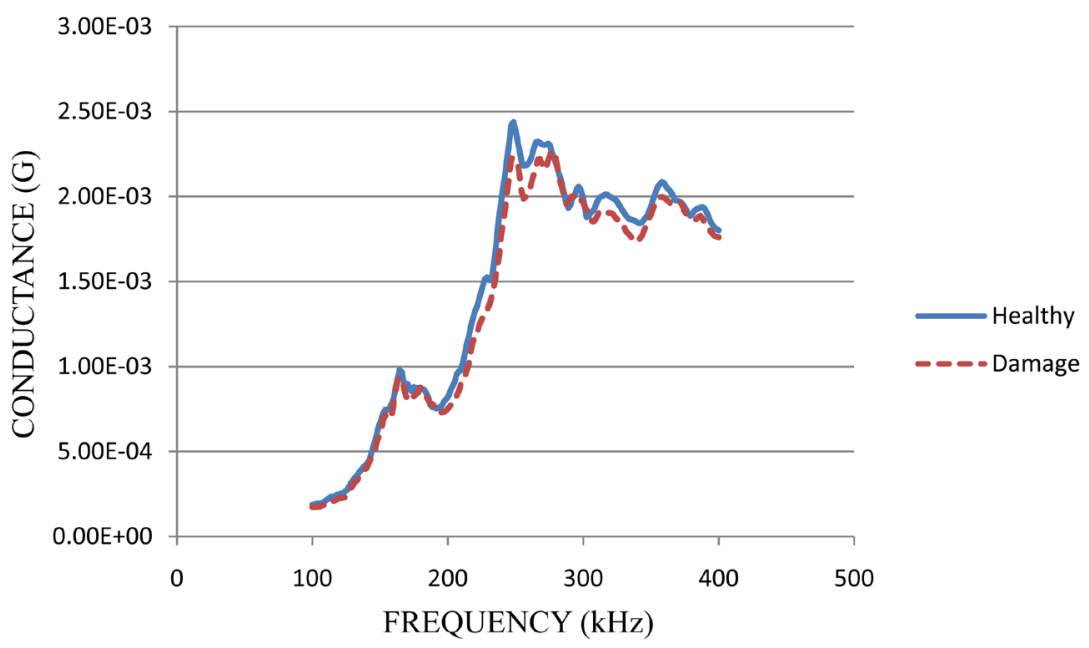

Figure 15. Conductance signature for healthy and damaged beam by embedded metal wire SMAG cylinder. 


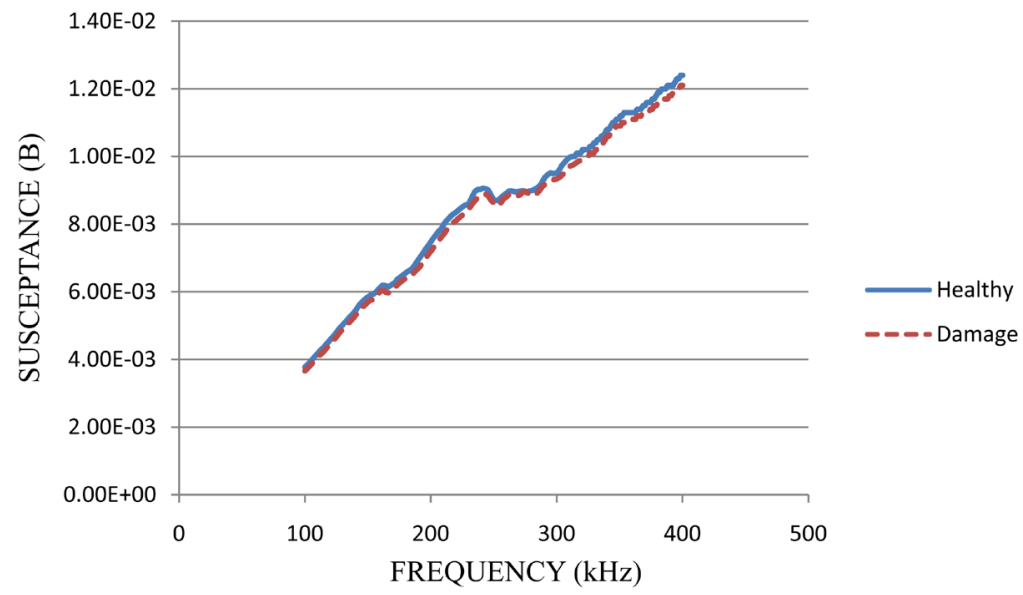

Figure 16. Susceptance signature for healthy and damaged beam by embedded metal wire SMAG cylinder.

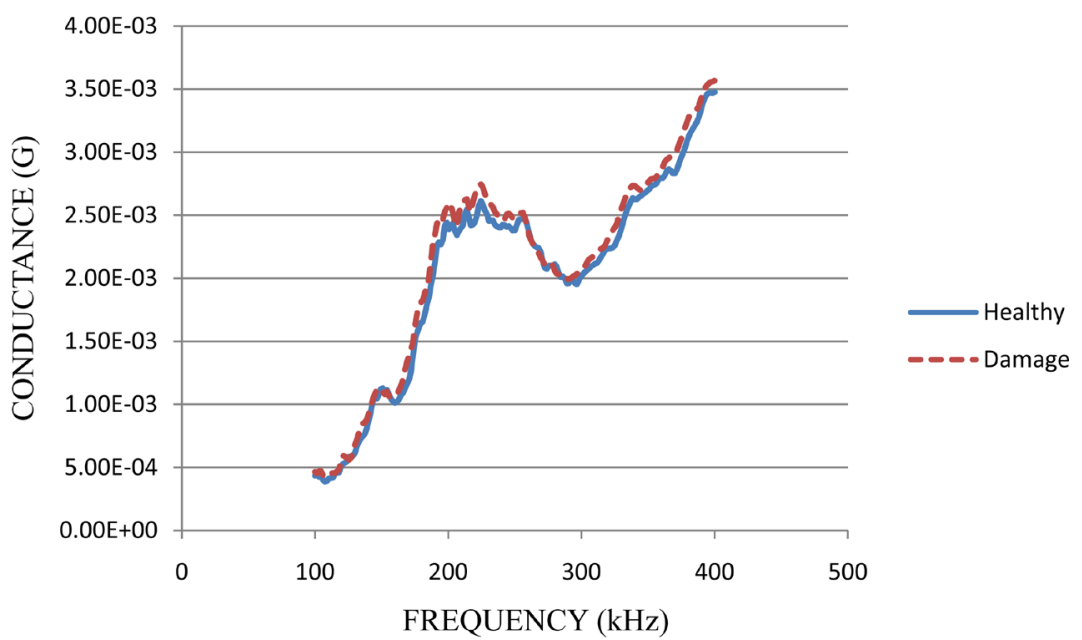

Figure 17. Conductance signature for healthy and damaged beam by embedded CVS.

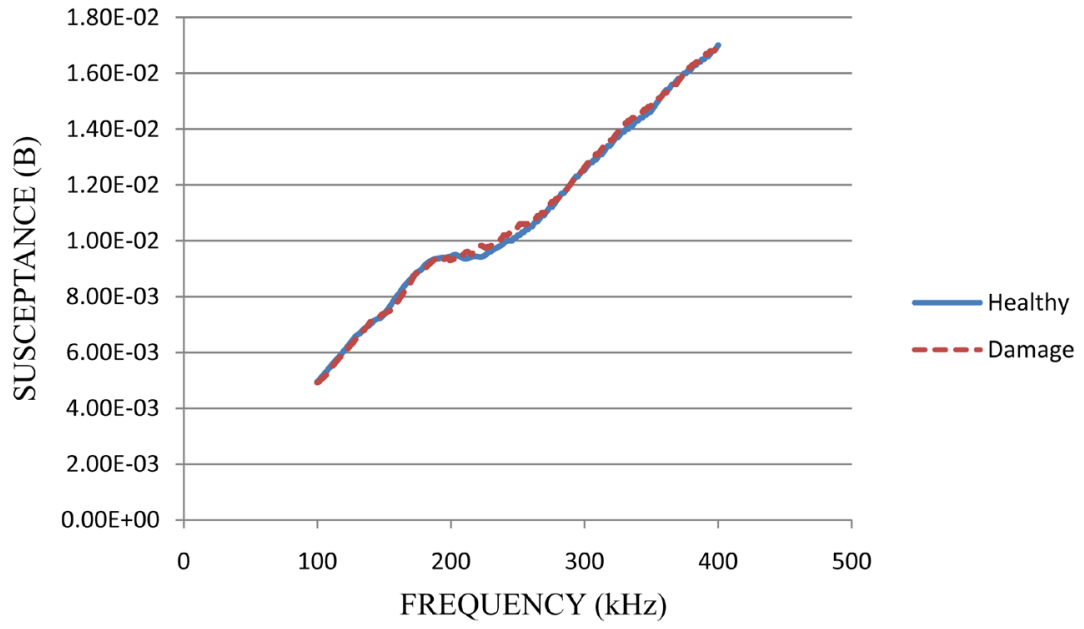

Figure 18. Susceptance signature for healthy and damaged beam by embedded CVS. 


\subsubsection{RMSD Index}

The severity of damage was obtained by using root mean square deviation technique (RMSD) as shown in Figure 19. The damage index recorded by SMAG brick was $10.02 \%$, by using metal wire SMAG cylinder was $7.23 \%$ and with CVS was found to be $7.51 \%$ between frequency ranges of $100-400 \mathrm{kHz}$. It is well established that both SMAG brick and metal wire SMAG cylinder are as effective as CVS in detecting incipient level damages.

\subsection{Response of Embedded SMAG in Varying Orientation and Surface Bonded PZT}

\subsubsection{Response for Healthy and Damaged Condition of Embedded SMAG and Surface Bonded PZT}

This section compares the conductance and susceptance response of the two embedded SMAG oriented in two typical configurations i.e. horizontal and vertical and one surface bonded PZT patch. All the signatures were plotted and compared for each stage.

Figure 20 and Figure 21 show conductance and susceptance signature for healthy and damaged beam by $\left(0^{\circ}\right)$ SMAG. Figure 22 and Figure 23 show conductance and susceptance signature for healthy and damaged beam by $\left(90^{\circ}\right)$ SMAG. The conduc-

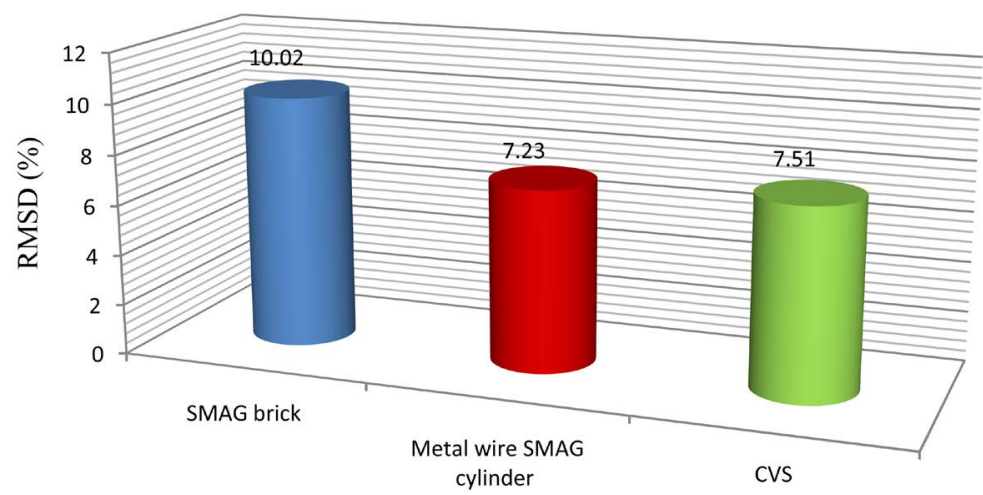

Figure 19. RMSD index for beam.

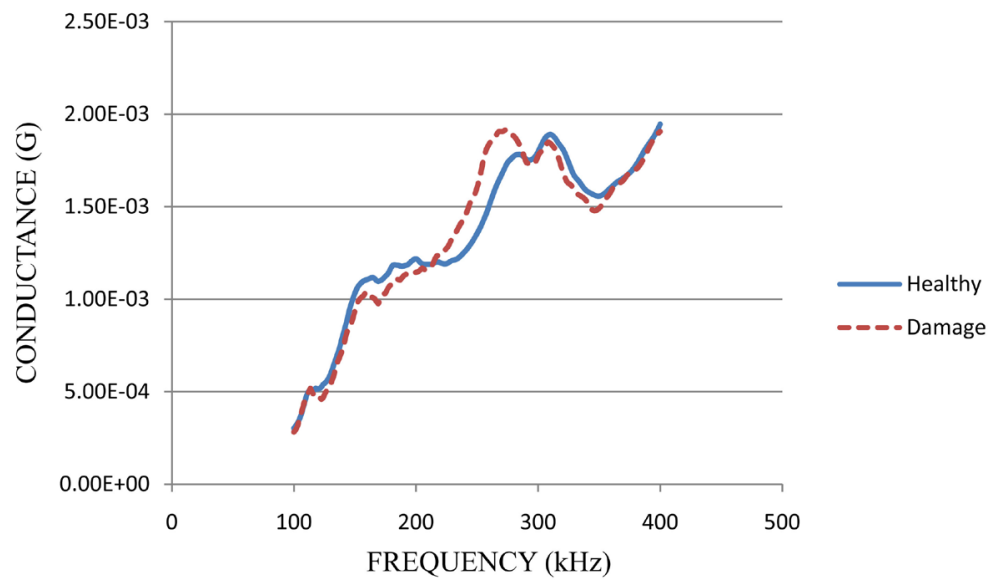

Figure 20. Conductance signature for healthy and damaged beam by $\left(0^{\circ}\right)$ SMAG. 


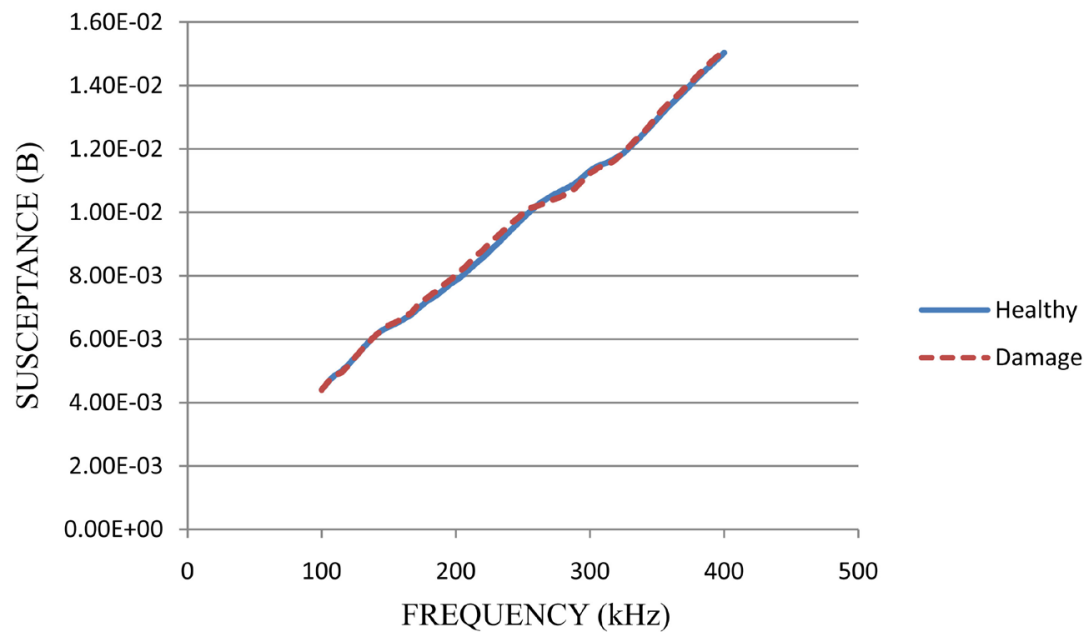

Figure 21. Susceptance signature for healthy and damaged beam by $\left(0^{\circ}\right)$ SMAG.

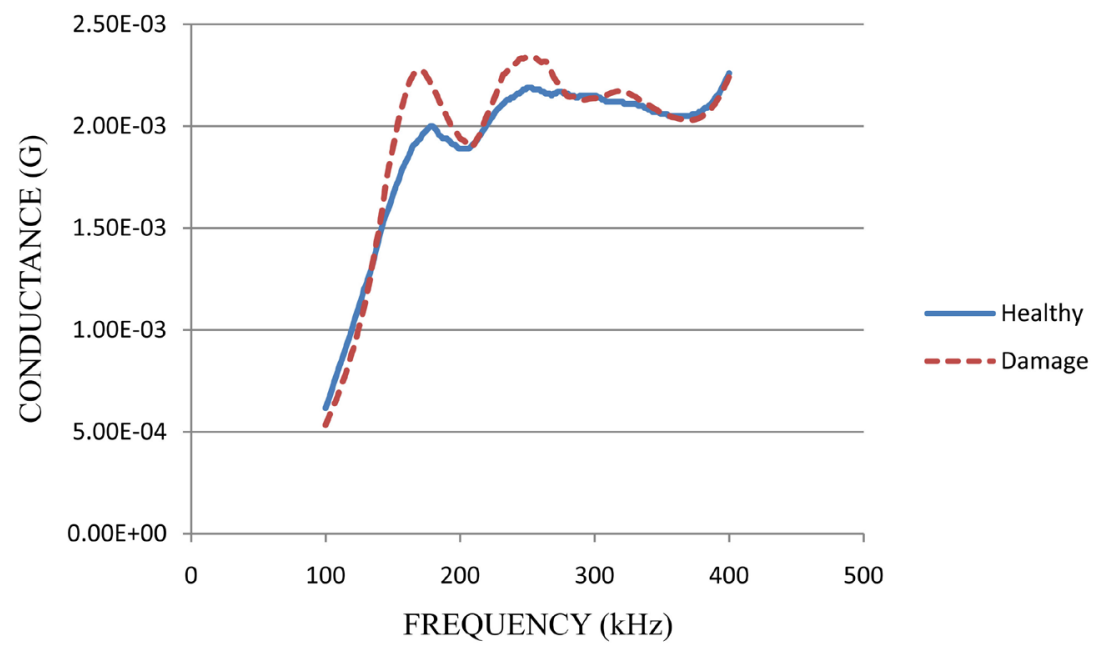

Figure 22. Conductance signature for healthy and damaged beam by $\left(90^{\circ}\right)$ SMAG.

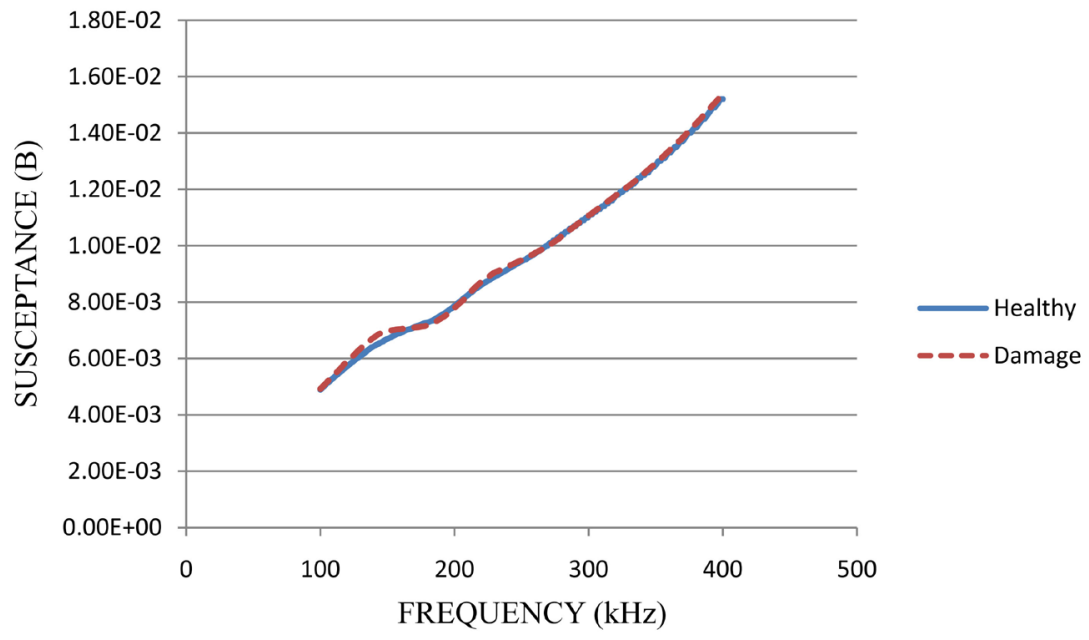

Figure 23. Susceptance signature for healthy and damaged beam by $\left(90^{\circ}\right)$ SMAG. 
tance and susceptance signature by surface bonded PZT are shown in Figure 24 and Figure 25 respectively.

\subsubsection{RMSD Index}

The damage index is shown in Figure 26. Since crack occurred nearer to the horizontal $\left(0^{\circ}\right)$ configuration SMAG, the RMSD recorded was $8.01 \%$ and that by the vertical $\left(90^{\circ}\right)$ configuration SMAG was $6.47 \%$. The RMSD recorded by surface bonded PZT was found to be highest as $50.50 \%$ since crack occurred exactly at the surface bonded PZT as shown in Figure 27, due to which surface bonded PZT was excessively effective in detecting crack.

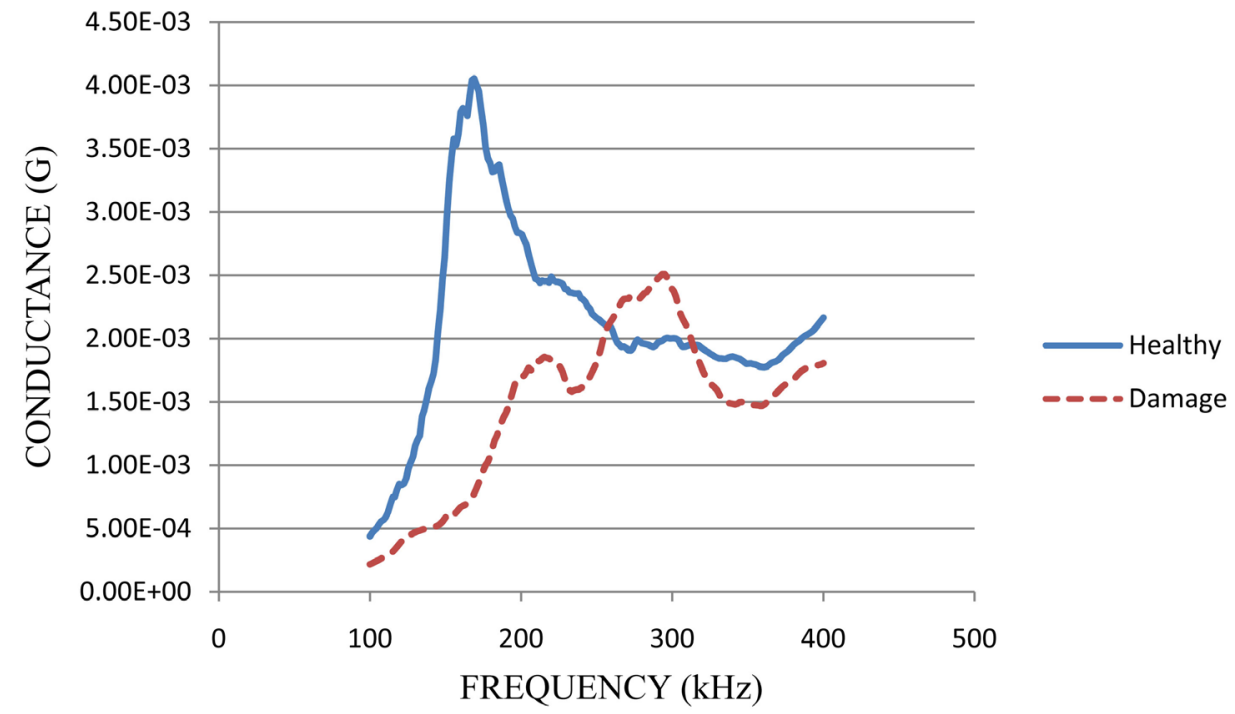

Figure 24. Conductance signature for healthy and damaged beam by surface bonded PZT.

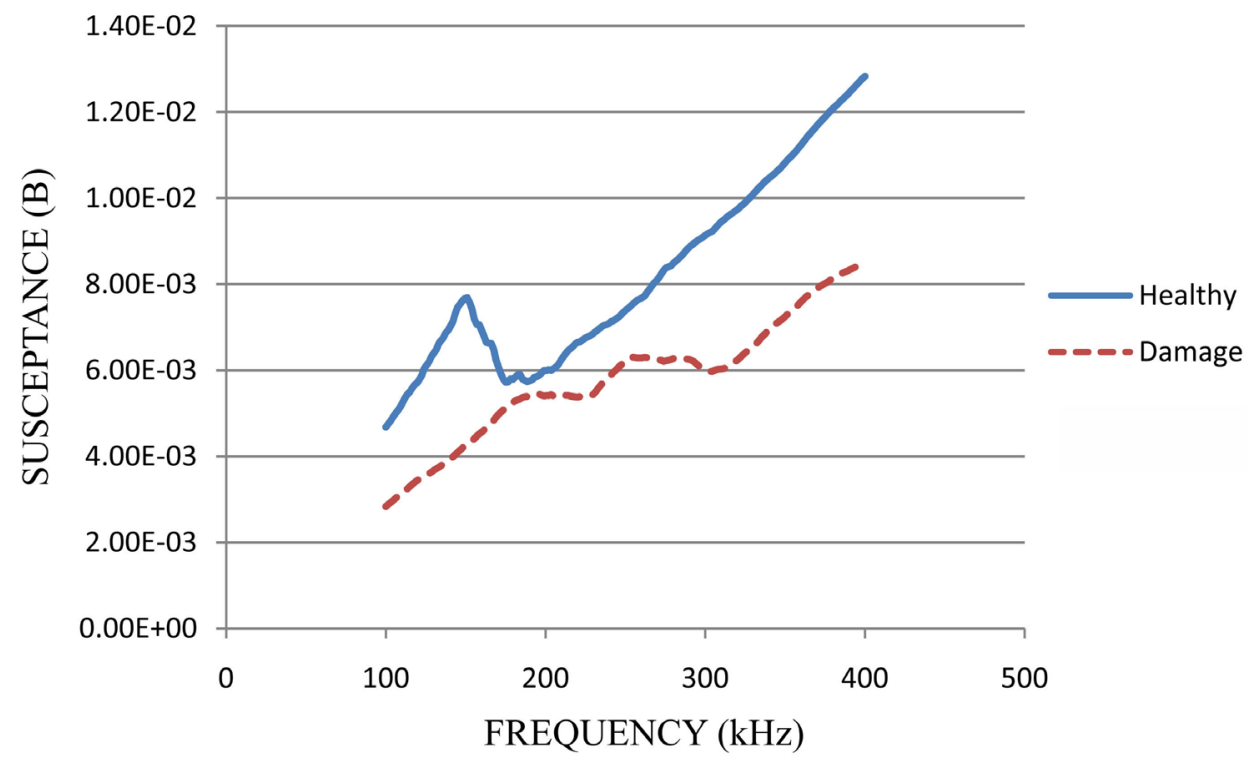

Figure 25. Susceptance signature for healthy and damaged beam by surface bonded PZT. 


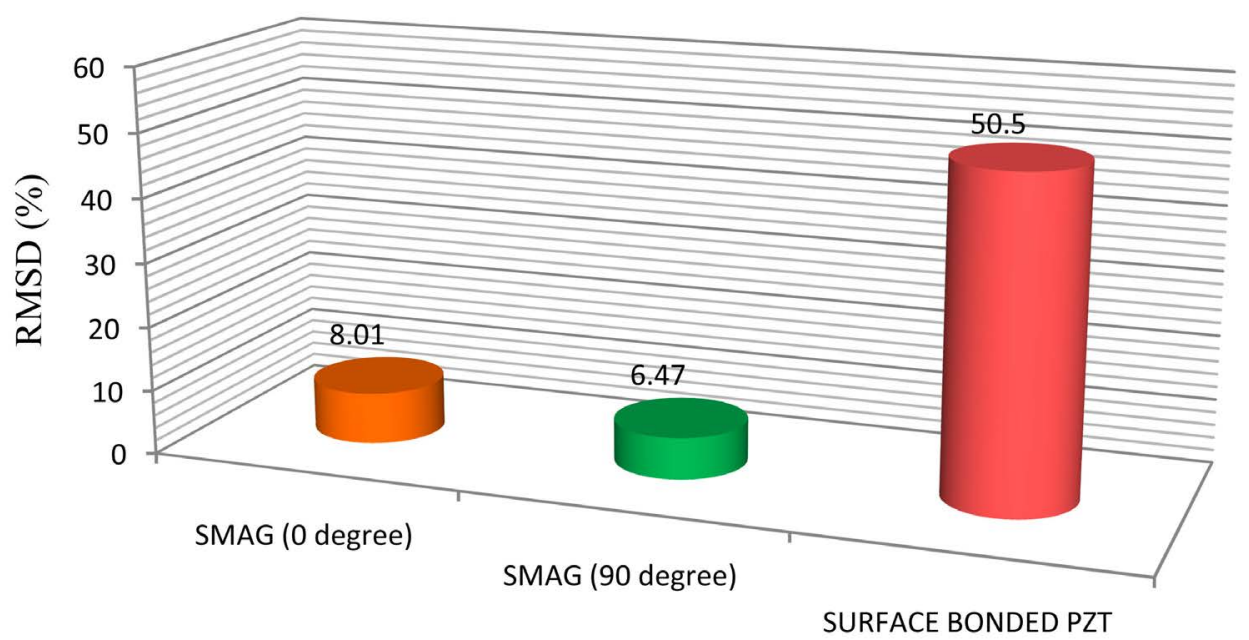

Figure 26. RMSD index for beam.

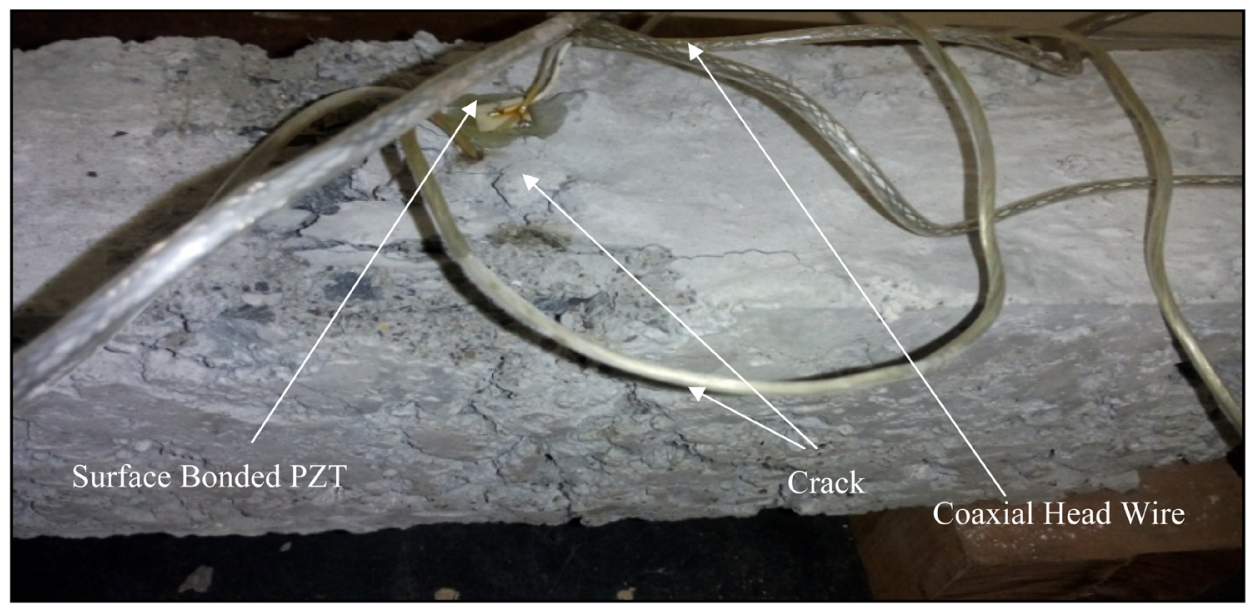

Figure 27. Crack occurred exactly at the surface bonded PZT.

\section{Conclusions}

This experimental work has presented a method to monitor the damages in concrete structure using embedded SMAG. It was verified from the results that the incipient level damage could be easily identified by lateral and vertical shifting of peaks. Since the same SMAG act as actuator and sensor, this saves the number of transducers and the associated wiring. Being high frequency technique, signatures have no interference with noise. It is well established from the first experiment that damage sensitivity of embedded SMAG depends on its location from damage and varies, i.e. nearer the location of embedded SMAG from damage, more is the sensitivity. By comparing the conductance and susceptance signatures obtained from indigenously prepared SMAG with the standard CVS, it was well established that the SMAG was also equally effective in detecting damage as damage detected by CVS for the same structure.

The second investigational study presented the comparison of SMAG embedded in two different orientation i.e. horizontal $\left(0^{\circ}\right)$ and vertical $\left(90^{\circ}\right)$ for their sensitivity to- 
wards conductance of RC beam and it was found that conductance peak was the highest in vertical $\left(90^{\circ}\right)$ SMAG within less frequency range. Hence, it can be advised to ensure the orthogonal positions of SMAG while using in embedded positions in real life structures. Health monitoring of structure using embedded SMAG is a better alternative for conventional tedious and time consuming SHM techniques with economy.

\section{References}

[1] Shanker, R. (2009) An Integrated Approach for Structural Health Monitoring. Indian Institute of Technology, Delhi.

[2] Annamdas, V., Yang, Y. and Soh, C. (2010) Impedance Based Concrete Monitoring Using Embedded PZT Sensors. International Journal of Civil and Structural Engineering, 1, 414-424.

[3] Wang, D.S., Li, Z., Zhang, S.S. and Zhu, H.P. (2013) Experimental Study on Sensitivity of Embedded PZT Impedance Transducers to Crack Damage of Reinforced Concrete Beam. The 13 th International Symposium on Structural Engineering.

[4] Khante, S.N. and Gedam, S.R. (2016) PZT Based Smart Aggregate for Unified Health Monitoring of RC Structures. Open Journal of Civil Engineering, 6, 42-49.

[5] Dumoulin, C., Karaiskos, G. and Deraemaeker, A. (2015) Monitoring of Crack Propagation in Reinforced Concrete Beams Using Embedded Piezoelectric Transducers. In: Ohtsu, M., Ed., Acoustic Emission and Related Non-Destructive Evaluation Techniques in the Fracture Mechanics of Concrete, Woodhead Publishing, Cambridge, 161-175. http://dx.doi.org/10.1016/B978-1-78242-327-0.00008-8

[6] Kaur, N., Gupta, N., Jain, N. and Bhalla, S. (2013) Integrated Global Vibration and LowCost EMI Technique for Structural Health Monitoring of RC Structures Using Embedded PZT Patches. Proceedings of UKIERI Congress on Innovations in Concrete Construction, B. R. Ambdekar National Institute of Technology, Jalandhar, 5-8 March 2013, Paper No. UCC-488.

[7] Song, G.B., Gu, H.C. and Mo, Y.-L. (2008) Smart Aggregates: Multi-Functional Sensors for Concrete Structures-A Tutorial and a Review. Smart Materials and Structures, 17, Article ID: 033001. http://dx.doi.org/10.1088/0964-1726/17/3/033001

[8] Negi, P., Kaur, N., Bhalla, S. and Chakraborty, T. (2014) Experimental Strain Sensitivity Investigations on Embedded PZT Patches in Varying Orientations. Proceedings of 9 th Biennial Conference on Structural Engineering Convention (SEC 2014), New Delhi, 22-24 December 2014, 2615-2620.

[9] Visalakshi, T. and Bhalla, S. (2014) Reinforcement Corrosion Assessment Capability of Surface Bonded and Embedded Piezo Sensors for RC Structures. Journal of Intelligent Material Systems and Structures, 26, 2304-2313.

[10] Xu, B., Li, Z. and Dyke, S.J. (2015) Interface Debonding Detection for an Irregular Complex Multi-Chamber Steel Reinforced Concrete Column with PZT Measurements. 11 th International Workshop on Advanced Smart Materials and Smart Structures, Technology University of Illinois, Urbana-Champaign, 1-2 August 2015..

[11] Wang, D.S., Zhang, J.B. and Zhu, H.P. (2015) Embedded Electromechanical Impedance and Strain Sensors for Health Monitoring of a Concrete Bridge. Journal of Shock and Vibration, 2015, Article ID: 821395. http://dx.doi.org/10.1155/2015/821395

[12] Talakokula, V., Bhalla, S., Bhattacharjee, B. and Gupta, A. (2015) Non-Destructive Assessment of Rebar Corrosion Based on Equivalent Structural Parameters Using Peizo-Transducers. Current Science, 108, 1890-1900. 
Submit or recommend next manuscript to SCIRP and we will provide best service for you:

Accepting pre-submission inquiries through Email, Facebook, LinkedIn, Twitter, etc. A wide selection of journals (inclusive of 9 subjects, more than 200 journals)

Providing 24-hour high-quality service

User-friendly online submission system

Fair and swift peer-review system

Efficient typesetting and proofreading procedure

Display of the result of downloads and visits, as well as the number of cited articles

Maximum dissemination of your research work

Submit your manuscript at: http://papersubmission.scirp.org/

Or contact ojce@scirp.org 